\title{
Refractory Colorectal Carcinoma
}

National Cancer Institute

\section{Source}

National Cancer Institute. Refractory Colorectal Carcinoma. NCI Thesaurus. Code C147982.

Colorectal carcinoma that does not respond to treatment. 